\title{
The Factors Affecting Jordanians Housewives Consumption Behavior: A Qualitative Approach
}

\author{
Mohammad Ibrahim Obeidat ${ }^{1}$, Abdullah Oweidat ${ }^{2}$, Nazieh Hamdi $^{2}$, Zaid Mohammad Obeidat ${ }^{3}$ \\ ${ }^{1}$ Professor, Department of Business, Amman Arab University, Jordan \\ ${ }^{2}$ Professor, Department of Education, Amman Arabic University, Jordan \\ ${ }^{3}$ Assistant Professor, Department of Marketing, University of Jordan, Jordan \\ Correspondence: Mohammad Ibrahim Obeidat, Professor, Department of Business, Amman Arab University, \\ Jordan.
}

Received: March 1, 2018

Accepted: April 4, $2018 \quad$ Online Published: April 23, 2018

doi:10.5539/ibr.v11n5p110

URL: https://doi.org/10.5539/ibr.v11n5p110

\begin{abstract}
Based on the findings of semi-structured interviews with $(\mathrm{N}=129)$ Jordanian housewives, this study examined the psychological, social, and marketing influences on the purchase and consumption behavior of Jordanian housewives. Overall, the findings of this study showed that the purchase decisions of the housewives were motivated by necessity to satisfy basic needs and the family appeared to be the main influencer affecting the housewife purchase decision. With regards to the factors prohibiting consumption, inflation appeared to be the main factor discouraging housewives from making purchases. A number of managerial implications and suggestions are also presented.
\end{abstract}

Keywords: consumer issues, Jordan, public policies, buying behavior

\section{Introduction}

Families are the main component of any society in the world, that is due to them being the ones who present ideas of purchase, determine their time and place, and determine the quantities purchased to meet the needs of these families (Solomon et al. 2016). In our current societies, families are forced to modify and develop their commodity and service needs as a result of their ever changing psychological and social needs (Obeidat, 2017). Moreover, since housewives have the most influence on the purchasing behavior of the family, various studies and scientific research have focused and continue to focus on their views of the factors affecting the purchase behavior of the family (Schiffman and Wisenblit, 2014). Consequently, this study will mainly focus on the attitudes of the Jordanian housewives toward the purchasing process and the role of psychological and social factors affecting their consumption behavior.

The current difficulties in the Middle East have triggered a series of economic issues to the Jordanian consumer (Ammonnews, 2012). From the continuous increase in inflation rates, increasing taxes on almost every product category, decline in income levels, the shrinking of the middle class, to the youth unemployment levels reaching almost 30\% (Obeidat, Obeidat, Obeidat, and Xiao, 2016). Consequently, the importance of this study is that the so-called Arab Spring has begun to fade now, which necessitates the need to identify the changes that have occurred in the patterns of consumption and consumption of families in general in light of the current socio-economic political reality.

The importance of this study stems from the fact that it examines the psychological and social factors affecting the purchasing decisions in the Jordanian family from the housewives point of view of. The identification of these factors influence on the consumption behavior of the family as well as determining the impact of the family and reference groups and their social status on purchasing and consumption decisions of the Jordanian housewives will help in finding solutions that helps correct errors in this behavior, which in turn, will positively affect the family and the general economy, in addition to increasing the sense of economic security in the family and on the health of family members psychological and social wellbeing.

As a result, this study will aim to identify the most influential factors affecting purchasing and consumption in the Jordanian family, In addition to determining the underlying motives of the families before and during the purchase. 


\section{Literature Review:}

It should be noted that there are dozens of studies that have attempted to identify the different effects of psychological, social, demographic and cultural factors on the purchasing and consumer behavior of individuals and families, in multiple societies and in different environments (Schiffman and Wisenblit, 2014; Cross, and Plank, 2015; Hartmann et al. 2017).

Pride, (2008) and Avello et al. (2011) points to the effect of psychological factors on consumer behavior such as motivations, direction, quality, learning and type, as well as the influence of beliefs and attitudes previously held by the consumer about the product of interest. Kytö et al. (2017) examined the influence of the consumer emotional state and found a positive link with the purchase intention and decision.

The study of Murray, (1991) has indicated that consumer purchasing activity is affected by previous marketing experiences in addition to activities that are implemented to satisfy the needs and family desires. Alekam et al. (2017) and Slater et al. (2010) also examined the impact of the four p's on the purchase and consumption behavior and found a significant influence. Another study of interest by Solomon, Dahl, White, Zaichkowsky, and Polegato, (2014), identified the impact of the availability of marketing information about the available goods and the associated quality and appropriateness of prices with purchasing behavior. The study of Minnema et al. (2017) also found an influence of reward programs on purchase intentions and behavior.

Furthermore, some studies focused on the impact of social factors on purchasing and consumer behavior, which included family, reference groups, relatives and cultural culture, among others, as well as the impact of cultural factors, culture and social classes (e.g. Schiffman, Kanuk, and Wisenblit, 2015). The study of Bai et al. (2015) in addition to Belk (1975) found an influence of social factors on the consumption behavior of a sample of household owners. In the same context, the Ali et al. (2017) study found a main predictive influence of the personal factors on the rules and fundamentals of purchasing and consumption. Other studies, such as Turley and Milliman, (2000), Mattila and Wirtz, (2008), Sherman, Mathur, and Smith, (1997) and Fransman and van Timmeren, (2017) all confirmed the impact of these psychological and social factors on purchasing behavior.

In Jordan, the study of Obeidat (2017), confirmed the impact of demographic, commodity and seller factors, as well as the impact of some external factors in influencing purchasing behavior. Consequently, due to the lack of studies examining consumption behavior and the factors affecting it in Jordan, this study aims to identify the impact of the psychological and social factors of Jordanian households on their purchasing and consumption decisions and at a difficult economic stage. After analyzing the previous studies the current study will try to answer the following question:

1- What are the main factors psychological, social, and marketing factors influencing the purchase decision of Jordanian housewives?

2- What is the most influential factor affecting the purchase decision of Jordanian Housewives?

\section{Methodology}

In order to examine the main factors affecting Jordanian housewives consumption and purchase behavior, an exploratory Qualitative approach was chosen from a purposive sample of $(\mathrm{N}=129)$ Jordanian housewives, a suitable sample size seeing as the majority of qualitative studies use a sample size between 50-70 (Saunders, Lewis, and Thornhill, 2007; Bryman, and Bell, 2011). Moreover, the study population included a selection of all the areas located in the Greater Amman City, which includes the different sectors of Jordanian society. The housewives were interviewed in malls, supermarkets and shops located in various areas of East and West Amman and the northern and southern suburbs. Students from the 27-year Master's Program at Amman Arab University and the University of Jordan conducted interviews in order to give sufficient time and attention to the studied sample.

Furthermore, the interview manual was presented to a group of experts specialized in marketing and psychological-social studies to verify the suitability of the questions for the objectives of the study. Semi structured interviews were used with each interview lasting between 35-40 minutes which helped the researchers to generate rich amounts of data that will help uncover the main patterns in their consumption behavior (Sekaran, 2003). Moreover, the interview manual included first a series of demographic question relating to the participants age, monthly income, monthly expenditure, family size, household status, educational level. The interview manual also included questions as (i.e. what are the main factors affecting your purchase decision, are you affected by the social culture in Jordan when you make a purchase?, can you describe how? And what are the main marketing factors that influence your decision when you make a purchase?). Additionally, as recommended, the authors provided the participants with a description of the purposes of the study in addition to 
guarantees that their answers will remain confidential (Saunders et al. 2007). Furthermore, the data collection process lasted for five months. A back translation was then performed as recommended by Saunders et al. (2007) to ensure the translated interview transcripts matched their original sources.

With regards to the data analysis, all the interviews were recorded manually. Moreover, while some initial thoughts were built before the data analysis began, the formal data analysis began after the data was collected. Thematic analysis was used to identify, analyze, and report the collected data (Creswell, 2009). This approach was used due to its flexible and simple structure, while having the ability to capture the evolving process under review (Braun \& Clarke, 2006). Consequently, the interviews' transcripts were first subjected to this analysis to provide a broad thematic portrayal of the collected data.

As recommended by Braun and Clarke (2006), six main steps were taken to analyze the data. First, to familiarize oneself with the collected data, as a result, considering that the data was transcribed manually, knowledge of the content of the interviews was achieved. Nevertheless, the transcribed interviews were read at least twice by the researchers to get a picture of the overall themes to emerge (Creswell, 2009). Second, to generate initial codes, the interviews were read again to identify the short divisions of the data. Overall, it was found that all of the collected data fitted into one of the four main initial codes generated. Third, to search for themes, the relevant preliminary codes were organized into possible themes (Braun \& Clarke, 2006). As recommended by Creswell, 2009 , mind map software was employed to unify and combine the initial codes to form the general main themes. In the Fourth step, to ensure that the four main themes make sense to the complete data set, the researchers reread all of the interviews to identify any new themes that might have been overlooked in any of aforementioned steps. All of the themes were reviewed and refined to ensure internal consistency within each category (Braun \& Clarke, 2006). In the final step, all of the emerging themes were given names and labels in order for them to be clarified and distinguished.

\section{Results}

\subsection{Sample Description}

Overall, 52.6\% of the housewives shopped only once weekly, whereby, 23.2\% went shopping 2-3 times a week, and $10.5 \%$ of the sample went shopping between (4-6) times per week. Only $14.7 \%$ of the sample went shopping only once every two weeks. With regards to participants' age, as seen in Table (1), the majority of participants were between $45-55 \%$ years old with $31.6 \%$ which indicates a good consumption experience. $23 \%$ were between $35-44$ years old, and $13 \%$ were between $25-34$ years old.

Table 1. Age of the participants

\begin{tabular}{lc}
\hline Age & Percentage \\
\hline Less than 25 & $12.6 \%$ \\
$25-34$ & $13.7 \%$ \\
$35-44$ & $23.1 \%$ \\
$45-54$ & $31.6 \%$ \\
$55-59$ & $11.6 \%$ \\
60 and above & $7.4 \%$ \\
Total & $100 \%$ \\
\hline
\end{tabular}

With regards to the martial statues of the housewives, Table (2) shows that the majority of the housewives were married with $82 \%, 5.3 \%$ were divorced, $3.2 \%$ were widowed, and $7.4 \%$ were single. Consequently, considering that the majority of the sample were married housewives, this shows that the majority of the sample had a good influence on the buying process and purchases of the family.

Table 2. Martial Statues

\begin{tabular}{ll}
\hline Marital status & Percentage \\
\hline Married & $82.1 \%$ \\
Divorced & $5.3 \%$ \\
Widow & $3.2 \%$ \\
Single & $7.4 \%$ \\
Other & $2.1 \%$ \\
Total & $100 \%$ \\
\hline
\end{tabular}

With regards to the income levels of the housewives, Table (3) shows that the majority of the housewives earned between 500-999 Jordanian dinars, followed by 250-499 JD's, with only 10.6\% earning over 2000 JD's. 
Table 3. Income levels:

\begin{tabular}{ll}
\hline Income levels & Percentage \\
\hline Less than 250 & $4.2 \% \%$ \\
$250-499$ & $23.2 \% \%$ \\
$500-999$ & $36.8 \%$ \\
$1000-1499$ & $15.8 \% \%$ \\
$1500-2000$ & $9.5 \% \%$ \\
$2000-2999$ & $5.3 \%$ \\
3000 and above & $5.3 \%$ \\
Total & $100 \%$ \\
\hline
\end{tabular}

With regards to the participants employment status, Table (4) shows that the majorities of the housewives were either unemployed with $49 \%$ or retired with $11.6 \%$. which shows signs of difficulty in making purchase decisions.

Table 4. Employment status

\begin{tabular}{ll}
\hline Employment & Percentage \\
\hline Full time in governmental sector & $10.5 \%$ \\
Full time in private sector & $10.5 \% \%$ \\
Free lance & $9.5 \%$ \\
Retired & $11.6 \% \%$ \\
Unemployed & $49.5 \%$ \\
Other & $8.4 \%$ \\
Total & $100 \%$ \\
\hline
\end{tabular}

Moreover, with regards to the educational level of the participants, Table (5) shows that the majority of the sample had a bachelor degree with $35 \%$, followed by a high school certificate with $25 \%$, and a diploma with $23 \%$.

Table 5. Educational level

\begin{tabular}{ll}
\hline Education & Percentage \\
\hline Middle school & $5.3 \%$ \\
High school & $25.3 \% \%$ \\
Diploma & $23.2 \%$ \\
Bachelor & $35.8 \% \%$ \\
Masters & $9.5 \%$ \\
PHD & $1.1 \%$ \\
Total & $100 \%$ \\
\hline
\end{tabular}

Overall, the findings first indicated that the majority of housewives had a reasonable proportion of purchasing and consumption experiences. However, the majority of the housewives had monthly incomes of less than 1,000 dinars. This is a significant financial burden for these families. Furthermore, $49.5 \%$ were retired or currently do not work which puts an additional financial burden on families, especially that the rise in prices for goods and services continues without any regard to the purchasing capacity of the majority of families in the middle and lower classes, which may reach up to $(80 \%)$ of the total families. Additionally, the results indicate that $35.8 \%$ of housewives have a bachelor's degree, which indicates a reasonable degree of awareness and knowledge of purchasing and consumption indicators. The percentage of housewives who were willing to purchase was always (87.4\%), while the percentage of female housewives who did not have a desire to purchase all the time was only $(12.6 \%)$.

\subsection{Purchase Motivations and Restrictions}

With regards to the purchase motivations, data analysis first showed as seen in Table (6) that $66 \%$ of respondents identified actually needing the product as their main reason for any purchase they make. This issue was heavily linked to the food and beverages category of products with $78 \%$ of the sample. Generally, these increases don't come as a surprise considering that with the continuous price increases in Jordan, consumers often resort to buying their basic necessities. As one of the participants explains:

"With the continuous inflation of prices, which is not accompanied by any increases in our Monthly income, we have to make do with what we have, which only covers our basic needs for food, gas, and electricity"

Additionally, $15 \%$ of the sample identified that their reason for purchase was not necessitated by an actual need but out of a sudden urge to buy. This motivation often accompanies acts of impulsive and compulsive buying (Pride and Ferrell, 2016). This finding is consistent with previous findings in the literature that associate females with higher degree with impulse buying (Schiffman and Wisenblit, 2014). This motivation was found to be associated with mostly shopping and luxury products such as clothing as seen by the comment below: 
"Honestly, I don't know why I buy sometimes, often I see a pair of shoes or dresses that I don't actually need but I just have to have them, shopping always changes my mood"

The third and fourth motivations were related to promotional factors with $18 \%$ of the sample. In this situation respondents were either wanted to try a new product or they were influenced by situational factors such as price discounts. Evidence from the literature supports these findings as many studies have established the influence of promotional factors on consumption behavior (Pride and Ferrell, 2016), as one participant explains:

"very often I don't want to buy, but with economic situation a lot of firms are doing heavy promotions to sell their stock, so I can get product that I won't normally buy at cheaper prices, so that what motivates me to buy"

Table 6. Factors encouraging Consumption

\begin{tabular}{lc}
\hline Purchase motivation & Percentage \\
\hline Home Supplies & $66.3 \%$ \\
Impulse & $15.8 \%$ \\
To try a new product & $11.6 \%$ \\
Promotional influences & $6.3 \% \%$ \\
Total & $100 \%$
\end{tabular}

With regards for the factors the discourage housewives from purchasing, Table (7) shows that the main factor restraining purchase for the housewives was the inflation of prices of product with $39 \%$ of the sample. In Jordan, the inflation of prices was seen as one of the main issues troubling the Jordanian consumer (Obeidat et al. 2016). The increases were seen in almost every sector in Jordanian market from the food and beverages sector, to gas, solar, and electricity and housing. This factor was heavily linked to the younger segment of our sample. The second factor was related to the low income levels of participants which can't let them afford to buy products outside of necessities. This factor was reported by $4.4 \%$ of respondents and is related to the first inflation category. This issue also appeared to be related to the youth segment of our sample. These two factors are explained by one participant below:

"one of the main problems we are facing in Jordan is the continuous inflation of prices, which is not accompanied by any increase in our incomes, and to make matters worse, we can barely afford to buy our weekly needs as it is"

Additionally, $16 \%$ of the sample also identified that sometimes the crowding in the store is what cause them to withhold the purchase. Generally, this finding is supported by previous findings in the literature as the store crowding has been found to cause consumers to turn away from purchases and even leads them to acts of misbehavior (Harries and Reynolds, 2009). Moreover, respondents also cited the method of product display as also one of the main reasons that often leads them to withhold purchases with $10 \%$ of the sample. Another $19 \%$ of the sample identified the low quality of products as the reason they don't purchase often. This finding does not come as a surprise especially with continuous reports of official governmental departments finding large shipments of expired products such as white and dark meat, medicines, and convenience products (Ammonnews, 2016). Finally, $12.6 \%$ of the sample identified the bad customer service provided to them in store as the reasons they refrain from purchase and consumption. This factor was found to largely influence purchase, purchase intentions, and acts of complaining and revenge (Obeidat et al. 2017).

Table 7. Factors restricting consumption

\begin{tabular}{ll}
\hline Purchase restrictions & Percentage \\
\hline Inflation & $38.6 \%$ \\
Low income levels & $4.4 \%$ \\
Crowding & $16 \%$ \\
Method of display & $10.5 \%$ \\
Low quality of products & $19 \%$ \\
Customer service & $12.6 \%$ \\
Total & $100 \%$ \\
\hline
\end{tabular}

\subsection{Social Factors}

With regards to the social factors that influence the housewives purchase decision, Table (8) shows that family was viewed as the main factor influencing the housewives purchase decision with $52 \%$ of the sample. This is consistent with previous findings that the family plays a large role in what the person purchases (Schiffman and Wisenblit, 2014). In addition, it also supports the previous finding earlier that the reason most housewives purchases is to buy product that are supplies for the house as one participant explains:

"like I mentioned before, my family takes most of my time, I rarely buy anything for myself, neither does my husband, so most of our purchases are centered to what kids want" 
Moreover, Table (8) also shows that the housewife social class also dictated what she buys with $32.6 \%$ of the sample. This finding is also consistent with previous studies which show that the consumer social class influence what he/she buys (Solomon et al. 2016). As seen buy one of the participants comments below, the social class the housewives belonged to, dictated what they had to buy even that in some circumstances she could not afford it:

"you have to keep up with appearances, we can hardly afford anything right now and in this economy, but we have to keep our lifestyle consistent with our social circle because this society its all about appearances and I don't want my kids to feel they are less than anyone else "

The third social factor related to the housewives cultural values with $9.5 \%$. As seen by the comments of one of the participants below, the cultural values seemed to highly influence what the housewife bought for her family. This finding is also supported by findings in the literature (Pride, 2008) that demonstrate the influence of the values and culture on consumer behavior.

"When we have a gathering for my husband family or mine for example, we are forced to buy products that are out of our price range; nevertheless, we have to buy something that honors them so we won't feel ashamed"

Finally, the fourth and final social factor related to the reference group of the housewives with $6.3 \%$ of the sample. As explained by the one housewife below, the influence of the reference groups such as friends and co-workers influenced what the housewife bought or didn't buy. This finding is also hugely supported in the literature (Schiffman and Wisenblit, 2014).

"am mostly influenced by what my friends say or recommend, in some cases they have more experience than me so I always rely on their judgment"

Table 8. Social influences on consumption

\begin{tabular}{ll}
\hline Social influences & Percentage \\
\hline Family & $52.6 \%$ \\
Social class & $32.6 \%$ \\
Cultural Values & $9.5 \%$ \\
Reference group & $6.3 \%$ \\
Total & $100 \%$ \\
\hline
\end{tabular}

4.4 Psychological Factors

With regards to the psychological influences on the housewives purchase decision, Table (9) highlights that the main factor the made housewives shop was to avoid thinking about problems and reduce stress with almost 50\% of the sample. Generally, links between shopping and stress reduction were found in the literature (Pride, and Ferrell, 2016). In this case, the housewives went shopping in order to avoid thinking about the problems she is facing, clear her head, and reduce the stress she is feeling as explained by one housewife below:

"I don't know, most of the time I go shopping to clear my head and think of other matters that don't disturb me, shopping always changes my mood"

Furthermore, the second factor related to the housewives getting rid of boredom with $27.4 \%$. As seen by the comments of one of the participants below, this factor also relates to the first where in both shopping is used to change the mood. This finding is also reinforced by findings in the literature (Murray, 1991) that demonstrate the influence of the shopping as mood changer in consumer behavior.

"I like to keep myself occupied because I get bored very easily, so whenever I have nothing to do I go to shop something and sometimes I spend hours looking around before I buy something"

Moreover, Table (9) also shows that the housewives sometimes shop because they like to acquire things and like the feeling of having possessions. This notion is highly related to the materialistic personality in consumer behavior (Schiffman and Wisenblit, 2014). This factor was reported by $23.2 \%$ of the sample and as seen by one of the participants comments below, this personality trait highly influenced their purchase behavior:

"Honestly, I shop because I like to possess things, whether it jewelry, clothes, or cars, I really like the feelings of having things and I really like the feeling of having things that are mine"

Table 9. psychological influences on consumption behavior

\begin{tabular}{lc}
\hline Psychological influences & Percentage \\
\hline To clear my head & $49.2 \%$ \\
Out of boredom & $27.4 \%$ \\
Materialism & $23.2 \%$ \\
Total & $100 \%$ \\
\hline
\end{tabular}




\section{Discussion}

Based on a qualitative sample of $(\mathrm{N}=129)$ Jordanian housewives, this study examined the motivation and factors affecting purchase and consumption behavior. Moreover, this study identified three main set of factors that influence the purchase decision of the Jordanian housewives. In terms of psychological factors, the majority of purchase decisions were performed as a distraction and as a way for the housewives to clear their heads. In terms of social factors, family appeared to be the main influencer on the purchase decision. With regards to the factors prohibiting consumption, inflation appeared to be the main factor discouraging housewives from making purchases.

Overall, the findings of this study show that the reasons behind the purchase of housewives were mainly to meet the needs of their homes and followed by purchasing just for the sake of doing so. Only a small proportion of the sample bought just to try a new product or because of marketing influences. Moreover, the reasons that discouraged housewives of buying were the high prices, lack of income, and overcrowding in shopping places, in addition to the poor quality of goods. Generally, these findings are supported by previous findings in the literature that shows the difficult economic conditions in Jordan such as the high inflation and unemployment rates and low income levels (Obeidat et al. 2016). However, it is the first time in the Jordanian context that factors such as crowding of shopping stores and the low quality of products has been mentioned. Consequently, providing better store designs and queue systems should minimize the appearance of crowding if firms wish to encourage consumers to buy. More importantly, the governmental observation of the prices can help reduce the issue of inflation and therefore should be increased. While the mainstreams of suppliers in Jordan are influenced by the economic conditions, some still increase their prices without any consideration to the diminishing buying power of the consumer. Therefore, increasing the governmental oversight could help in decreasing the negative consequences of these issues to a degree.

With regards to the social factors influencing the purchasing decision of housewives, the family was found to mainly influence the purchases of the housewives followed by the social class the consumer supposedly belongs to. As a result, for firms wishing to increasing traffic at their stores, placing family appeals in their promotions and targeting kids with their offers could help do that. Additionally, consumer agencies and governmental bodies that are supposed to handle consumer issues should design and implement awareness campaigns that educate consumers about the correct purchase patterns and about spending within their means. Consequently, consumption rationalization campaigns should also be implemented to decrease unnecessary shopping acts that eventually harm the buying power of the consumer.

With regards to the Psychological factors affecting Jordanian housewives consumption, three main factors appeared to highly influence the purchase decisions. The first two related to using shopping as a way to reduce boredom and a distraction. While the third related to a personality trait. Consequently, considering the negative consequences unneeded shopping could have on the Jordanian family financial statues, awareness campaigns regulated by the responsible bodies could also showcase the negative consequences of these actions in this regard. While the current society and philosophy of most firms tend to promote an ideology of consumption, specific measures has to be taken in some cases to intervene and to restrain some promotional campaigns to ensure that the consumers expenditure won't cause negative effects on his/her wellbeing especially in the cases where the firms promotions encourage materialism.

Based on the results of this qualitative study, it is necessary for the factors identified here to be tested using a quantitative design in order to obtain results that can be disseminated to larger sections of Jordanian housewives. Second, it is also necessary to deal with a large random or a non-random sample that reflects the different demographics associated with the psychological, social and cultural components of the Jordanian society. Therefore, the coverage of the sample items for all twelve governorates of Jordan may be essential to obtain results that can be circulated to the Jordanian society.

\section{References}

Alekam, J. M. E., Nik Mat, N. K., \& Md Salleh, S. (2017). The Significant Role of Communication, Price, and Quality in Creating a Brand Trust to Achieve Purchase Behavior Antecedents and Consequence of Consumer Brand Trust. International Journal of Supply Chain Management, 6(4), 260-268.

Ali, A., Xiaoling, G., Sherwani, M., \& Ali, A. (2017). Factors affecting Halal meat purchase intention: Evidence from international Muslim students in China. British Food Journal, 119(3), 527-541. https://doi.org/10.1108/BFJ-10-2016-0455

Ammonnews. (2012). "Toukan: The Arab spring has influenced the economy of Jordan", available online at: 
http://www.ammonnews.net/article.aspx? articleno=1075 60 .

Avello, M., Gavilan, D., Abril, C., \& Manzano, R. (2011). "Experiential shopping at the mall: influence on consumer behavior". China-USA Business Review, 10(1).

Bai, Y., Yao, Z., \& Dou, Y. F. (2015). Effect of social commerce factors on user purchase behavior: An empirical investigation from renren. Com. International Journal of Information Management, 35(5), 538-550. https://doi.org/10.1016/j.ijinfomgt.2015.04.011

Belk, R. W. (1975). Situational variables and consumer behavior. Journal of Consumer Research, 2(3), 157-164. https://doi.org/10.1086/208627

Braun, V., \& Clarke, V. (2006). Using thematic analysis in psychology. Qualitative research in psychology, 3(2), 77-101. https://doi.org/10.1191/1478088706qp063oa

Creswell, J. W. (2009). Mapping the field of mixed methods research.

Cross, J., \& Plank, R. (2015). "Purchase Behavior by Commodities Buyers; Some Strategic and Tactical Insights". In Proceedings of the 1989 Academy of Marketing Science (AMS) Annual Conference (pp. 436-439). Springer, Cham. https://doi.org/10.1007/978-3-319-17055-8_88

Fransman, R., \& van Timmeren, A. (2017). Psychological and social factors underlying pro-environmental behaviour of residents after building retrofits in the City-zen project. Energy Procedia, 122, 1051-1056. https://doi.org/10.1016/j.egypro.2017.07.477

Hartmann, M., Cash, S. B., Yeh, C. H., Landwehr, S. C., \& McAlister, A. R. (2017). "Children's purchase behavior in the snack market: Can branding or lower prices motivate healthier choices?" Appetite, 117, 247-254. https://doi.org/10.1016/j.appet.2017.06.014

Kytö, E., Järveläinen, A., \& Mustonen, S. (2017). Hedonic and emotional responses after blind tasting are poor predictors of purchase behavior. Food Quality and Preference. https://doi.org/10.1016/j.foodqual.2017.05.015

Mattila, A. S., \& Wirtz, J. (2008). The role of store environmental stimulation and social factors on impulse purchasing. Journal of Services Marketing, 22(7), 562-567. https://doi.org/10.1108/08876040810909686

Minnema, A., Bijmolt, T. H., \& Non, M. C. (2017). The impact of instant reward programs and bonus premiums on consumer purchase behavior. International Journal of Research in Marketing, 34(1), 194-211. https://doi.org/10.1016/j.jiresmar.2016.08.001

Murray, K. B. (1991). A test of services marketing theory: consumer information acquisition activities. The Journal of Marketing, 10-25. https://doi.org/10.2307/1252200

Obeidat, M. I. (2017). The Consumer, The consumed, \& the Devastated: A longitudinal study of Jordanian Housewives. International Business Research, 10(7), 178-184. https://doi.org/10.5539/ibr.v10n7p178

Obeidat, Z. M. (2015). Youth Unemployment in Jordan: Causes \& Solutions. International Journal of Business Research, 3(15), 77-90. https://doi.org/10.18374/IJBR-15-3.7

Obeidat, Z. M., Obeidat, M. I., Obeidat, A. M., \& Xiao, S. H. (2016). Jordanians Economic Challenges \& Aspirations: An Empirical examination. International Journal of Business and Economics Research, 3(5), 29-37. https://doi.org/10.11648/j.ijber.20160503.11

Pride, W. (2008). Marketing. Cengage Learning.

Pride, W. M., \& Ferrell, O. C. (2016). Foundations of marketing. Cengage Learning.

Saunders, M., Lewis, P., \& Thornhill, A. (2007). "Research Methods for Business Students", 4th edition, Prentice Hall Financial Times, Harlow.

Schiffman, L. G., \& Wisenblit, J. (2014). "Consumer behavior" 11th edition. Prentice Hall.

Schiffman, L. G., Kanuk, L. L., \& Wisenblit, J. (2015). Consumer Behavior. $12^{\text {th }}$ edition, Prentice hall

Sekaran, U. (2003). "Research Methods for Business: A Skill Building Approach", 4th edition, New York: John Wiley and Sons.

Sherman, E., Mathur, A., \& Smith, R. B. (1997). Store environment and consumer purchase behavior: mediating role of consumer emotions. Psychology and Marketing, 14(4), 361-378. https://doi.org/10.1002/(SICI)1520-6793(199707)14:4<361::AID-MAR4>3.0.CO;2-7

Slater, S. F., Hult, G. T. M., \& Olson, E. M. (2010). Factors influencing the relative importance of marketing 
strategy creativity and marketing strategy implementation effectiveness. Industrial Marketing Management, 39(4), 551-559. https://doi.org/10.1016/j.indmarman.2008.03.007

Solomon, M. R., Bamossy, G. J., Askegaard, S., \& Hogg, M. K. (2016). "Consumer Behavior: A European Perspective" $6^{\text {th }}$ edition. Pearson

Solomon, M. R., Dahl, D. W., White, K., Zaichkowsky, J. L., \& Polegato, R. (2014). "Consumer behavior: Buying, having, and being" (Vol. 10). Pearson.

Turley, L. W., \& Milliman, R. E. (2000). Atmospheric effects on shopping behavior: a review of the experimental evidence. Journal of Business Research, 49(2), 193-211. https://doi.org/10.1016/S0148-2963(99)00010-7

\section{Copyrights}

Copyright for this article is retained by the author(s), with first publication rights granted to the journal.

This is an open-access article distributed under the terms and conditions of the Creative Commons Attribution license (http://creativecommons.org/licenses/by/4.0/). 